\title{
Ethical dilemmas: balancing choice and risk with a duty of care in extending personalisation into the care home
}

\section{Emma Miller and Karen Barrie}

\begin{abstract}
The article reports on the perspectives of senior care staff as part of an action learning study exploring the possibilities for personalisation in care homes. Behind the conceptual sword and shield of choice-and-control associated with personalisation in the UK, lie irreconcilable flaws, thrown into sharp relief in the care home context. Personalisation, which originated in community-based social services during the mid-2000s, has recently been extended into UK care homes. This service development has been stimulated by a desire to promote a humane response to caring for an ageing population, whilst containing costs. Seemingly promoting a relational approach, personalisation also entails consumerist underpinnings, with consequent tensions resulting in weakened policy mechanisms. Discussing findings pertaining to 'food and eating', the article illustrates the complex interplay between supporting resident capabilities in the context of poor staff ratios; when choice isn't really choice at all; balancing choice, risk and the duty of care and responding to diverse perspectives about what matters. This complexity reflects the highly skilled nature of care work as promoted by care ethicists. The tensions permeated care home life and found parallels in the wider system of care. Honesty about the limitations of the choice-and-control mantra is essential if ethical care of older people living in care homes is to be achieved. Far from being a limiting case for personalisation, the care home constitutes fertile ground for exposing and exploring the shortcomings of the 'logic of choice' and for advancing a more relational, inclusive and sustainable conceptualisation of personalisation.
\end{abstract}

Key words: personalisation, care homes, ethic of care, consumerism, personal outcomes 
Acknowledgements: We would like to thank in particular the carers who gave their time to participate in this research, and wish to acknowledge their considerable knowledge and skills, which significantly influenced the direction of the research. 


\section{Introduction}

Population ageing is now a truly global phenomenon (United Nations 2019), prompting different responses internationally. Throughout OECD countries it is generally acknowledged that residential care will remain part of future public care provision for older people, but with the proviso that this continuation will require radical change. Across the United Kingdom (UK), task forces and commissions have considered the future of residential care as broadly understood (Scottish Government 2014, Demos 2014) and care homes in particular (JRF 2009). As is the case in diverse OECD countries, financial concerns have resulted in long term cuts to service provision in the UK (Lymbery 2013, Young 2020) at the same time as populations are ageing. This is the context within which personalisation has emerged as a significant policy development. Personalisation can be characterised as focusing on the particular needs of individuals rather than a one-size fits all approach to services, while self-directed support focuses more on the control people can exert over the definition of needs and how they should be met through an individual budget (Boxall et al 2009, Lloyd 2010). In policy terms, personalisation incorporates both elements (Lloyd 2010).

Although personalisation, which originates in community care, is increasingly promoted as the means of providing services more generally, it is a deeply contested concept (Needham 2011). As well as the challenges entailed in promoting greater 'choice and control' in the context of welfare retrenchment, concerns have been expressed about individualist assumptions at the heart of relevant popular policy mechanisms, both in general terms (Needham and Glasby 2014) and particularly for older people (Lloyd 2014). The strategic emphasis on expanding personalisation into the complex environment of care homes for older people therefore requires careful consideration. 
This article reports on a study undertaken in a Scottish local authority which explored understandings of and possibilities for personalisation from the perspectives of a seldom heard group, frontline care home staff. As a separate but linked initiative on personalised planning with care home residents was simultaneously being undertaken by local authority staff, it was agreed that the authors would not overburden residents with a similar set of demands and work with staff only. This paper begins by describing the complexity of the current UK care home landscape, the ambiguous nature of personalisation and the different possibilities for its translation into care homes for older people. The study aims, conceptual framework and methods are then set out before reporting and discussing the key findings on the topic of food and eating. This fundamental area of everyday life illustrates a range of tensions and contradictions generated by choice-based personalisation mechanisms which permeate all aspects of care home life and which find parallels in the wider system.

The article argues that the care home constitutes fertile ground for exploring and exposing key limitations of the 'logic of choice' (Mol 2008). We consider the potential of the ethic of care promoted by Tronto (1993) to help redraw boundaries of independence and partnership between people using services, family carers and professionals. Fisher and Tronto (1991) have developed a four-point schema for a political ethic of care: attentiveness (caring about), responsibility (taking care of), competence (care giving), and responsiveness (responding to the needs of the cared-for). Whilst in agreement that having choices is one of several outcomes contributing to wellbeing and quality of life, we wish to advance a more relational, inclusive and sustainable conceptualisation of personalisation, and consider the policy and societal implications.

\section{The UK care home landscape}


Two types of care homes are provided in the UK: those providing personal care such as assistance with personal hygiene, dressing, and eating and drinking (formerly termed residential care homes); and those which provide nursing care in addition to personal care (formerly termed nursing homes). Care homes are highly complex organisations, influenced not only by demographic and societal changes, but also by government policy, legislation and the prevailing economic climate (Royal College of Nursing 2012). In the UK the statutory duty to provide long-term residential care for people unable to care for themselves for reasons of 'age or infirmity' was introduced in 1948 and largely enacted through local authority provision until the late 1970 s when free market principles were introduced into public services (Midwinter 2011). This paved the way for the implementation of the NHS and Community Care Act (1990), separating purchaser and provider functions, transferring state funding to cash-limited local authority budgets and intensifying the policy aspiration for older people to be cared for at home. Local authorities were also vigorously encouraged to purchase from independent organisations rather than deliver services themselves, and to arrange that users of social care services of all types paid towards their costs (Midwinter 2011).

The Competition and Markets Authority (CMA) calculate that there are around 5,500 different providers in the UK operating 11,300 care homes which provide care to approximately 410,000 residents (CMA, 2017). Around 95\% of care home beds are provided by the independent sector (both for-profit and charitable providers) and local authorities generally commission care services from independent care providers. Responsibility for funding has increasingly shifted to individuals. The CMA estimate that the average cost for a self-funder in 2016 was $£ 846$ per week (nearly $£ 44,000$ per year), while local authorities on average paid $£ 621$ per week. The UK care homes sector is worth around $£ 15.9$ billion a year (CMA 2017). 
The persistent UK policy emphasis on people being cared for in their own home for as long as possible, coupled with more recent moves to promote earlier hospital discharge, have resulted in people entering care homes later when they are older, frailer, with complex and multiple conditions, and often high levels of cognitive impairment (Froggatt et al. 2009). The result is that, inevitably, people now need more care and support to understand and meet their particular needs and aspirations, but this has not been reflected in staffing levels, skill mix, status, pay or conditions (Kennedy 2014). Alongside restrictive funding arrangements, care homes suffer from a poor public image. Workforce recruitment, demoralisation and retention difficulties are commonplace (Kennedy 2014). The negative public perception of care homes also presents significant challenges for older people and their families, with the move to a care home increasingly associated with failure, loss and guilt (ibid), rather than finding the care and support needed to continue to lead as fulfilling a life as possible in the changed circumstances of advanced old age (Hurtley 2004, Barnes 2012).

Across the UK, and internationally, aspects of care homes recognised as in most need of improvement are supporting the workforce to flourish in increasingly complex environments, quality of care and the quality of life and wellbeing of residents (Jeon et al. 2015, Kadri et al 2018). In the UK, as in other European countries, staff who work in care homes are generally low paid and work in conditions of high pressure with staff shortages and high staff turnover (Franklin 2014, Kadri et al 2018].

Since the mid-2000s, UK social care policy has advocated personalisation as integral to enhancing the wellbeing of people using community care services and its introduction into the care home setting may appear a logical extension. Despite sounding inherently positive, personalisation is however a highly ambiguous concept (Needham 2011) and the nature of this ambiguity in general terms is summarised before considering particular concerns regarding the 
value of personalisation for older people and the implications for its translation into care homes for older people.

While thus far, we have considered the backdrop to UK policy, health and social care policy devolved to Scotland from 1997. While the purpose of this study is not comparative, there are opportunities to consider whether and how divergence in personalisation policy might offer fresh hope in finding means of progressing some of the policy and practice conundrums emerging from the literature, and this study.

\section{Conceptualisations of personalisation}

Personalisation arose as a response to paternalistic practices and a one-size-fits-all, bureaucratic and in some ways ineffective approach to public service provision (Miller 2011). Different interpretations and modes of implementing personalisation have emerged in tandem. Here we consider two broad approaches to understanding the personalisation agenda.

\section{Relational understandings of personalisation}

The relational conceptualisation of personalisation as understood here is founded on a broad understanding of personal outcomes initially promoted by the Social Policy Research Unit at York University, (Qureshi et al 1998) then subsequent work at the University of Glasgow (Petch et al 2013) further developed with services in Scotland (Cook and Miller 2012, Miller and Barrie 2015). Outcomes for family or unpaid carers form part of this framework of understanding, with the need to consider, negotiate and agree outcomes at the centre of an exchange model of practice (Smale et al 1993, Miller and Barrie 2015).

Relationships are the mechanism for establishing trust and rapport, reaching shared understandings, careful consideration of what constitutes reasonable risk, negotiation of what's 
possible and appreciation of the contributions that everyone involved can make to achieving health, wellbeing and quality of life outcomes. In comparing self-assessment with more collaborative approaches including a personal outcomes approach, Keyes et al (2014) found that people using services benefitted from attentive and caring input from a professional in defining their needs and outcomes, and indeed choices, thus supporting relational autonomy.

An outcomes approach incorporates maintenance outcomes such as feeling safe, having things to do and seeing people, consistent with wider quality of life. It includes change outcomes including managing symptoms, improving confidence and recovering self-esteem, consistent with tackling barriers to quality of life and restoring capabilities. Thirdly, it also incorporates process outcomes such as being listened to, valued and treated with respect. This latter set of values is consistent with an ethic of care (Fisher and Tronto 1991) which we shall explore below and in which choices and preferences are embedded alongside other outcomes, rather than being the assumed primary driver. Indeed, this conceptualisation recognises that we are relational, interdependent beings and that authentic care is grounded in positive relationships. In the context of a care home particularly careful attention and excellent observational skills are required by staff to understanding what matters to residents, many of whom may not be able to communicate their needs and outcomes verbally.

\section{Consumerist understandings of personalisation}

A predominant conceptualisation of personalisation employs an understanding of the person as a rational, autonomous consumer. This notion elevates the concepts of 'choice and control' (intended to convey individual empowerment with regard to service use). Such perspectives have understandably appealed to some within disability and other user movements. Their appeal is due to the promise to recognise claims for self-determination and to reduce an 
unwelcome dependence on professional service providers (Barnes 2012). However, this does not reflect the often very complex life circumstances faced by people using services; the collaborative and therapeutic practice which can be essential at point of crisis; and the safeguarding role of statutory services (Lymbery 2013). The consumerist focus on market mechanisms does not reflect the community development roots of social work (Lymbery 2013). Rummery (2011) recommends that consideration should be given to reconciling the disability rights emphasis of personalisation with a feminist demand for an ethic of care.

Concern is also evident with regard to the processes and mechanisms associated with choicebased individualised models of support and the allocation of individual budgets to afford users control over their support (Beresford 2014). Early signs from England showed that these added to rather than reduced the amount of time spent on form filling and bureaucracy (Samuel, 2010) with more recent and similar evidence from Scotland (Eccles and Cunningham 2018).

Policy on personalisation has differed across the UK, over time. The main policy mechanism in both Scotland and England is self-directed support (SDS). SDS has brought together contradictory elements from relational and consumerist agendas (Needham 2011). We now explore some contradictions within self-directed support before going on to consider how the identified tensions play out in the context of the care home.

\section{Self-directed support}

Further complications arise from the funding arrangements associated with self-directed support. Self-directed support incorporates the calculation of individual budgets and associated mechanisms, promoted as offering choice. Tensions arise when concepts of choice and control meet with funding restrictions and bureaucratic means of determining access. This can add 
layers of complexity, particularly for people with multi-morbidity and possible cognitive impairments.

While most health care in the UK has in the post-war decades been provided free at the point of use, funded by central government, social care is provided by local authorities, restricted through eligibility criteria and means tested. As the increased policy emphasis on self-directed support has coincided with a period of welfare retrenchment (Lymbery 2013), increasing numbers of older people, who tend to have higher needs for social care, are self-funding either due to failing to meet tighter eligibility criteria or because their assets are above the prescribed capital limit for state funding (Tanner et al 2017). In addition to the affordability gap faced by many people required to self-fund, there are concerns about the challenges of finding, arranging and managing care, particularly for older people with complex needs (Tanner et al 2017).

The systemic tensions described here are felt intensely by practitioners who are required to implement self-directed support. For many practitioners, the moral authority invested in 'choice and control' cannot easily be challenged (Needham 2011). They are compelled to demonstrate advocacy of a consumerist model presented as synonymous with person centred quality care, despite their own knowledge of the inconsistencies entailed, including overemphasis on the autonomous individual (O’Dwyer 2013).

Hart (2014) compares the gains that she has seen for working-age adults fully engaged in the process of organising their own care with the lack of change for older adults with cognitive impairments. Questioning the vastly different ways in which the 'personalisation box is ticked', she contrasts the 'shiny brochures all about user choice - local leisure centres versus day centres' with her own experience which often came down to 'one shower a day or two baths a week' and highlights that '[i]t is the dishonesty that is difficult to manage as a practitioner' 
(pp114-115). Recent research in Scotland similarly highlights the gap between the transformational promise of self-directed support and the mundane and intricate aspects of implementation (Eccles and Cunningham 2018).

\section{An alternative framing of personalisation: The Ethic of Care}

Consistent with broader understandings of personalisation as described above, the ethic of care conceptualises the person as a relational being whose survival and flourishing depends upon care (Tronto 1993). Importantly, it emphasises that while our interdependencies are most evident when we are very young, ill, disabled or have become frail in old age, dependency is not a failing but a vital part of the human condition. Rather than assuming rationality and privileging cognition, this understanding underscores to the need to handle the embodied nature of humanity and how this intersects with our own emotional responses to the processes of ageing and impairment (Barnes 2012). Considerations of our embodied nature expose the need for constant attunement to the contingencies and unpredictability of the body and the complex and erratic requirements of caring (Mol 2009).

The ethic of care literature has grown considerably over the past thirty years from its early considerations of care as a private, devalued and highly feminised practice to engage with care as a set of sensitising principles. These principles of attentiveness, responsibility, competence and responsiveness (Tronto 1993) and trust (added by Sevenhuijsen 1998 as both a condition for and outcome of care) give ethical content to four interconnected and equally necessary phases of care: caring about; taking care of; care giving; and care receiving. Separating out the different components of caring into the four phases, particularly the separation of 'taking care of' and 'care giving' restores the visibility of hands on care work obscured by the 
commodification of care. This allows for an understanding regarding the meeting of needs and aspirations that is not simply about individuals and the state allocating resources.

While the inequality and vulnerability present in many caring relationships are acknowledged, the framing of care work from the perspective of those who provide care has been heavily critiqued by disability scholars for leaving the role and the power differentials experienced by those who receive care underdeveloped (Morris 2004). This is an area where considerable work has been conducted in recent years. In particular, Barnes (2012: 74-82) illustrates how the principles can be used to support justified concerns about demeaning 'care' work practices that do not embody care. She also offers an important corrective, expanding upon the principles of trust and responsiveness to emphasise that the integrity of care is dependent upon the 'care receiver' as an active agent in the process. Personal outcomes thinking adds to this redress by foregrounding both the relationality of processes through which what matters to the person is understood and the active contribution of the person to the achievement of outcomes.

\section{Expanding personalisation into residential care}

The expansion of self-directed support into residential care settings is a more recent legislative development (Law Commission 2011, Care Act 2014, Self-Directed Support Act Scotland 2013) prior to which the sector remained relatively insulated from the above debate. While specific concerns have been expressed about the appropriateness and relevance of self-directed support mechanisms for older people living in care homes, particularly in view of the high levels of cognitive impairment amongst residents (Scottish Care 2012, DH 2012), Barnes (2011) argues that drawing a new moral boundary between those who can and those who are less easily able to exercise choice and control is ultimately unhelpful, serving to reinforce the marginalisation of the most vulnerable people. As a late entrant into the debate, the sector is 
arguably well placed to open the space for an alternative and potentially broader conceptualisation of personalisation within the policy sphere.

While there are echoes of different perspectives within the various residential care strategies, overall they constitute missed opportunities to advance fresh thinking. Instead the prevailing policy emphases on increased choice, control and independence are extended into the sector in a largely unreflective way, with the familiar hybrid of consumerist and seemingly progressive rights-based arguments imported with their ambiguities unresolved. The approaches taken to inform the strategies also indicate some of the ways in which the perspectives of those with direct knowledge of care home life may be suppressed, for instance with the hypothetical preferences of future users privileged over the 'low expectations' of older people currently living in care homes (Demos 2014). Alongside this, the direct contributions of those working at the point of care are either excluded from the deliberations on the grounds that they lack the authority to effect change (SG 2014) or characterised as 'traditional' or 'less radical' (Demos 2014).

Far from routine inclusion in decision-making, it has been previously noted that the personhood of staff in care homes needs to be attended to, alongside that of residents. Often motivated by the wish to genuinely care, care staff regularly feel out of control and pushed into a more instrumental form of care (Kadri et al 2008). Recent research on using evidence to improve services for older people confirms the continuing tendency to exclude practitioner perspectives in implementing change, particularly the voices of residential and domiciliary care staff. It also confirmed the added value of doing so in terms of outcomes for both staff and the people they care for (Andrews et al 2020).

The need to take cognisance of the knowledge and insights of those with direct experience of care home life is clear. If the chasm between personalisation policy and practice, 'between 
rhetoric and reality' (Hart, 2014, pp115-116) is to be bridged, she suggests 'the way through the murky water is to promote a culture of trust, honesty and responsiveness' by acknowledging current realities, that we have a long way to go and that 'we all have to listen harder'. This article reports on a study which explored the perspectives of care home staff to consider possibilities for advancing a broader and more inclusive conceptualisation of personalisation into the everyday realities of care home life.

\section{The Study}

This study was undertaken within a Scottish largely suburban local authority area, based in the central belt of the country. We describe the characteristics of the four participating care homes in further detail below. Our study ultimately aimed to increase understandings of the overarching challenges and opportunities associated with implementing a focus on personal outcomes for older people living in care homes. While our work with care staff was underway, the wider self-directed support project was taking place with a small subset of residents and families. To avoid duplication, our study did not involve residents directly. Rather, a key concern was to find out how staff access the perspectives of all residents, and particularly how they come to recognise the ways that people with profound cognitive and communication impairments continue to convey the things that matter to them until the end of life. It was also committed to supporting staff to recognise and articulate their own expertise, knowledge and insights and to develop a deeper appreciation of the often invisible work that care home staff do. To facilitate engagement with the epistemological implications of the study and to respond to practice concerns about the importance of trust, we employed the ethic of care as our conceptual framework, as summarised below.

\section{Sampling and Recruitment}


Invitations were issued to managers of all eight care homes which were already participating in the wider self-directed support project underway in the area. Four privately owned care homes with nursing self-selected to take part in the study. The study began with an initial meeting with the care home managers to introduce the components of a personal outcomes approach and gain their support. The managers were then asked to nominate between two and four senior care staff to participate. One care home, despite hosting the initial session, was unable to free up staff to attend and has subsequently closed. Another care home from a large UK private sector provider was the largest establishment, with 84 places. The remaining two care homes were both owned by another large UK private sector provider, with 40 and 60 beds respectively. The latter two homes changed ownership in 2017. This lack of stability in the local care home market corresponds with the CMA report (2017) which questions the sustainability of the sector as it is currently organised and financed.

A total of ten senior carers from the three remaining care homes participated. All were female, white and lived locally, consistent with the demographic profile of care staff in this locality. The participant age range spanned from $25+$ to $55+$ years and the length of time working in the care sector from eight to over thirty years.

\section{Ethical Considerations}

Ethical principles were adhered to, with all participating staff informed about the study purpose, what taking part would entail and how the generated data would be treated, stored and used for reporting purposes. They were also advised that they were free to choose whether or not to take part, and consent to audio record and transcribe the discussions was obtained before any data generation commenced. Confidentiality and anonymity were respected throughout. Ethic of care principles also informed our approach to the development of ethical research 
relationships (Ward and Gahagan 2010), particularly acknowledging the importance of trust, which is developed iteratively rather than established for good at the outset. On two occasions, staff had to leave the sessions, and we were subsequently informed that their participation had resulted in short staffing on the floor. Responsibility entailed thinking through who needed to be consulted at each stage and the ensuing practicalities, while competence concerned our aptitude to do the research, including our knowledge of the sector and prior experience of relating to staff. Responsiveness involved on-going sense-checking of emergent themes with staff, thus informing our collaborative approach to data generation.

\section{Data Generation Methods and Participation}

The initial plan was to facilitate four half day workshops over the period of two months, using an 'appreciative action learning' model. This model brings staff closer to their day-to-day work, rather than taking them away from it, and recognises that individuals learn best when they learn with and from each other (Sharp et al 2018). We sought to introduce staff to core concepts pertaining to appreciative, relational practice and personal outcomes, and to sense check and refine prompts that have worked in other contexts, particularly the outcomes framework (Cook and Miller 2012). The intention was to encourage staff to test out core concepts in practice and reflect on their application at the subsequent session.

Four action learning sessions were held over a five-month period within the participating care homes and all ten senior carers contributed enthusiastically. However, while at least one of the same two senior carers from one care home attended all four sessions, attendance by staff from the remaining two care homes was variable, limiting consistency. This pattern of attendance is indicative of the difficulties care homes experience in freeing up staff, to attend any nonmandatory training, because there is no slack in the system. 
Indeed, staff who did attend were often on annual leave or on their off days, or had to miss lunch or catch up with the day's workload before going off shift. The lack of continuity of action learning group membership hindered some study objectives but enhanced others. Opportunities for practice development, especially around recording, were inevitably limited. On the other hand, revisiting core concepts and returning to prompts intended only for the introductory session resulted in some reframing to reflect their specific meanings in this context. Holding the sessions within participating care homes was invaluable in supporting our understanding of how competing demands are experienced on the ground. The evident pressures on staff also made us more cognisant of the real challenges faced in achieving personalisation in care homes.

Audio recording the sessions seemed to increase participants' willingness to contribute openly. The carefully observed practice examples stimulated participants to reflect upon and share the various ways that they seek to understand and facilitate what matters to residents and introducing staff to our appreciative, relational approach encouraged them to 'have their say'. The sharing of emergent themes at the start of each session confirmed that they were being listened to, with previously unrecognised ways of knowing - 'the stuff they just do' - validated.

\section{Data Analysis: Food for Thought}

The four recordings from the sessions with staff were transcribed and a thematic analysis of the data was conducted using an inductive approach, drawing upon ethic of care thinking as described above and the wider literature as an interpretative framework. Given that there were four transcripts, the volume of data was not excessive. However, the content was rich and required some consideration against the original objective of exploring the potential for personalisation in care homes. We undertook initial coding manually, working independently in the first instance and then together compared our reflections before progressing to a second 
phase of coding and comparison of findings. We were both struck by the prevalence of 'food and eating' in the data and the place of choice within this. The findings in this article are presented under subheadings which emerged from this analysis.

The importance of food and eating within the data is consistent with their fundamental importance within care homes. They assume significance for medical, social and cultural reasons and there are diverse views as to the relative importance of these dimensions in the literature and in practice. Specifically, food and drink are essential to life and bring our embodied nature to the fore, including the challenges raised to ensure that people who are frail or have difficulty swallowing maintain adequate nutrition and hydration (Merrell et al 2012).

They are thus the subject of regulatory requirements and meeting these requirements calls upon multi-disciplinary expertise. Mealtimes play critical functions in care homes, providing temporal structuring to the day (ibid). While they can provide important opportunities for social interaction, people with eating difficulties may prefer to eat alone and some residents may find the eating difficulties of others off putting (ibid). Mealtimes can also be a source of added anxiety for people with dementia, with efforts to enhance the mealtime experience calling attention to the physical environment (Whear et al 2014) and expanding considerations beyond individual decision-making situations to encompass the competing needs and preferences of several residents.

The ambiguity surrounding what constitutes an ideal mealtime reflects the hybrid nature of the care home itself, which must variously try to meet individual needs for care, create a homely environment for people, provide a hotel-like service that accommodates diverse consumer preferences and protect residents from harm (Harnett and Jonson 2016). We therefore identified 
the capacity of 'food and eating' to illustrate and offer a focused discussion of the range of tensions and contradictions that were found to permeate all aspects of care home life.

Drawing upon the ethic of care framework and relating these findings to the personalisation literature, we also identified parallel tensions and contradictions in the wider system. These tensions draw out different interpretations of personalisation as identified above, which can be characterised mostly simply as a consumerist model based on choice versus a relational model aligned with an ethic of care. We present the key findings in the following section, before considering the ways in which the care home can be construed as a microcosm of the wider system in the discussion, throwing the muted concerns about the limitations of the 'logic of choice' (Mol 2008) into sharp relief.

\section{Findings}

The findings are clustered under the inter-related themes of 'supporting resident capabilities in the context of poor staff ratios', choice in the context of group living, when choice isn't really choice at all, balancing choice, reasonable risk and the duty of care, power differentials and hierarchies of knowledge and responding to diverse perspectives.

Just one pair of hands: Supporting resident capabilities in the context of poor staff ratios

The participants had all worked in the sector for many years and were aware that staffing levels had not changed despite the increased age and needs of residents and that this impacted upon residents:

We're aware that there a lot of restraints on staff time, which has a knock-on effect on what you do, and on residents [P6] 
Another member of staff highlighted the consequences of time constraints on their ability to support resident independence:

I also think that the time constraints we are under, we do take away their independence without thinking because we are under the pressure of time, but we need to encourage people [P3]

The requirement to be able to respond to the unpredictable and changing physical care needs of residents often dominated staff activities and meeting the simultaneous needs of several residents was incredibly difficult when you were 'just one pair of hands.' With respect to eating, many people required assistance and although 'if you put things in reach....they can do it - it just takes longer', the list of other tasks to be completed often resulted in staff 'doing things for people because it's quicker' [P6] - despite their best intentions.

Group divisions: choice in the context of group living

In addition to the perceived inadequacies of resident:staff ratios, group living inevitably presents difficulties to the provision of personalised care, with different residents having diverse and at times conflicting priorities and preferences. In the communal areas of the home, participants highlighted that their homes prioritised the nutritional needs of the most vulnerable people over the more social or cultural personal preferences of others, as illustrated by the following exchange between three care staff:

P2: You've got to be quiet in the dining room, but some people don't like quiet in the dining room, some people like a lot of hustle and bustle 
P7: Sometimes people like to sit at a wee table with the television so they can watch the news and things, whereas part of the policy from the care inspectorate is that they should have quiet time, so the TV and radio should be off

P3: Yes, but I think the idea of that is because it's for people who are very, very vulnerable and if distracted they won't eat at all and it has a knock on effect on their health

What made mealtimes enjoyable was also acknowledged as an important consideration, as was the need to find equitable solutions that accommodated everyone's preferences and staff were keen to ensure their own brand of social justice:

It's about communal living. It's not just about one person, it's about everybody [P1].

Consistent with previous studies in care homes, the participating staff found their own pragmatic ways to attend to and meet the different and at times competing needs of residents (Nolan et al 2004), often striking compromises by 'breaking the rules' (Kontos et al 2011): P7: Then you have people like this lady we have just now, if the news isn't on this woman won't sit down. If the television is on and you put her plate down she will sit down and she will eat it.... She doesn't want to sit in her room, she doesn't like being in there on her own... If it's person centred care, what do you do? We maybe have four people who need assistance with meals who sit at the other end of the dining room with us. The TV is not bothering them, but if the inspectorate come in we need to turn it off. You think we should be able to act naturally the way we do every day rather than putting on a show.

P3: An act, a display, yes

Here is an example of staff finding ways to accommodate different choices or preferences of residents around how they eat their meals, being hindered by expectations of regulatory requirements. This perceived need to 'put on a show' found expression in several different ways. 
False choices: when choice isn't really choice at all

The notion of 'putting on a show' was evident in situations where staff were being observed and particularly where choices could be offered in a seemingly straightforward manner, such as when offering menu options or serving drinks. The senior carers had worked in their respective homes for many years and were familiar with many residents' likes and dislikes. They did not feel that their wisdom and detailed knowledge of the residents were taken into consideration and utilised to achieve good personal outcomes for residents. Additionally they felt that they had to offer what felt like false choices when observed by inspectors or internal auditors:

The care inspectorate pulled up the deputy (manager) for not asking someone if he took sugar in his tea. But she knew that he didn't. [P1]

While acknowledging the value of checking in on preferences from time to time, one participant remarked that it was 'unnatural' to go around offering choices where the response was already known as it 'doesn't make people feel like it's their home'.

While knowing what residents like and what they don't can be construed as a form of paternalism, previous studies have found that residents may view staff knowledge of their food preferences as a positive aspect of care (Merrell et al 2012). It can also be helpful for people with dementia who may forget what they have ordered. Failure to act on this knowledge could be considered irresponsible and serve as a source of irritation. One participant referred to a resident 'who will tell you exactly what she is having to eat and if offered anything above that gets very agitated', especially if staff keep asking, adding 'it makes you feel as if you are being negative $[P 5]$. 
For people with dementia, it is recognised that anxiety levels can increase considerably at mealtimes (Whear et al 2014) and participants noted that choices could compound this:

With people with Alzheimers, dementia, you can make someone agitated by offering too much choice. They don't want to eat anything because they become so agitated ... Sometimes it's not as black and white... there's grey areas [P6].

The almost theatrical performance of offering choices from a pre-set menu was at odds with the more restricted choices about when to eat, where to eat and who with, with the diverse perspectives of different professionals and family members influencing and complicating such decisions. Participants did acknowledge that some residents continued to enjoy the opportunity to choose between food options. There was a sense however that scrutiny from managers or external bodies tended to focus on menu related choices rather than more fundamental variables influencing health, wellbeing and quality of life outcomes relating to food and eating.

Alongside personal preferences, participants were aware of the social implications of eating difficulties, which can result in residents withdrawing into their rooms and avoiding the use of communal spaces. Participants therefore had to try to strike a judgement between supporting resident choices, particularly those that would encourage eating, and being complicit in resident withdrawal.

Supporting choices and resident autonomy became increasingly problematic when what a resident wished to eat was deemed as having negative impacts on their health, when a resident had difficulty eating and particularly when a resident didn't want to eat at all, raising a series of ethical dilemmas. 
Ethical dilemmas: balancing choice, reasonable risk and the duty of care

Our participants all referred to key tensions between the ethical duties of providing care, protecting residents from harm and respecting their autonomy. The senior carers participating in this study were acutely aware of the importance and difficulties of finding an appropriate balance between these different ethical imperatives:

It's finding the balance. You can be very person centred, but if they don't want to get up and don't want to eat do you let them starve to death? You can't do that. Taking the difference between your duty of care and being person centred to them, it's a very fine line [P4]

They were also often aware of people's lives and preferences outside the home, and the importance of continuity, and sought to respect that:

People I have known about in the community have been built like sticks [P5]

We have a wee lady who has always been size 8 - she came in here and because she is underweight you have to fortify everything - she is not going to eat any more or change, but we still have to write the charts. Her weight stayed consistent [P4]

Our point is they (the professionals) are saying they (the residents) are underweight but they've never been fat, so who the hell are we to try and feed these people up when they don't want it? They are not used to big meals [P2].

Participants also connected with residents' more embodied forms of autonomy, such as spitting out food or closing their mouths, recognising their own discomfort in trying to persuade residents to eat:

(We're told) 'You need to get calories into someone'. Sometimes I don't feel comfortable in this role and force feeding in that they are clearly saying I've had enough [P5].

We don't have the right if someone has decided enough is enough [P7]. 
The discomfort the participants experienced was a reflection of both an appreciation that they were over-riding the resident's autonomy and of their own powerlessness to influence decisions about what mattered to the resident.

Group divisions: power differentials and hierarchies of knowledge

The importance of and ways of understanding what matters to the resident was an overarching theme.

The participants' accounts were riddled with missed opportunities by other professionals to engage with their particular type of knowledge. Participants were aware that their own situated knowledge of a particular resident was placed lower down the hierarchy than that of specialist professionals, which was often based on detached facts. For instance, when discussing one resident who only ate rice crispies, the participant drew upon particular, embodied knowledge that the lady in question could 'only manage six spoonfuls' - anything more and she would invariably be sick. However, the participant was persistently instructed to encourage the lady to eat more, with predictable consequences:

It's all about getting calories into her, but she ends up with nothing in her system [P2] Another participant expressed concern about the repetitious nature of one resident's prescribed, fortified diet:

We have a lady who has goitre and she can't swallow... and all her food is thickened. All she has is soup and ice-cream. I've already said to our kitchen this lady has watery porridge in the morning that's fortified with cream and it's got sugar and jam without bits in it and it's all to this consistency. At lunchtime she gets the soup and ice-cream. At dinner time she gets the same foods. That's enough to put anybody off [P7] 
They were also concerned that these more remote 'specialists' did not appreciate the practicalities and on occasions futility of implementing recommendations, such as modified diets and food charts:

It's time consuming and you are filling in these wee boxes and it makes no difference whatsoever [P3].

There was concern that some of the specialists had never met the residents they were making recommendations for. Consistent with relational understandings, there was some appreciation that dieticians were in short supply and also experienced time pressures and constraints: It can take months for the dietician to come in after we ask [P7]

The perceived hierarchy of knowledge played out in different ways, often resulting in a sense of frustration for senior carers. In the following example, there is hope that a nurse can have more influence on decision-making by a dietician:

The nurse spoke to the dietician the other day about the wee lady who only likes rice crispies....

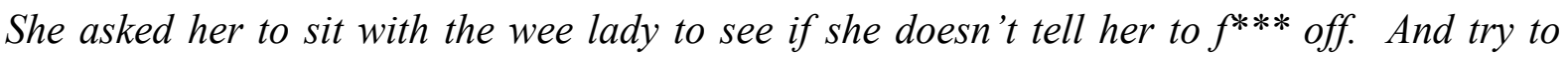
encourage her to do what she expects us to do because we are upsetting her and that's enough to put her off [P2].

While the support of the nurse was welcomed, there were also situations where different professional perspectives about priorities could compound the difficulties staff experienced.

Group divisions: responding to diverse perspectives about what matters

The participants highlighted that managing different disciplinary and regulatory perspectives was tantamount to a 'juggling act' [P3] again impacting on the authenticity of the care they provided:

Do you not also think that at times when it comes to eating and drinking, and you have all the different agencies involved, and they want to know, what have you done about this? And what 
have you done about that? And that has an impact on being person centred because your concern is I'm going to get into trouble because they're not eating and drinking properly, because I'm allowing her to do what she chooses, so that also comes into choice [P7]

The extent to which what matters to the person was taken into account at each level of decision making was found to vary considerably, and participants indicated that these different negotiations took place in isolation. The net result was that often the most implicit but complex negotiation fell to frontline staff helping older people to negotiate everyday life in the home. Thus seemingly 'basic tasks' require skilful negotiation between the duty to meet needs for care, to respect autonomy in its various expressions, avoid potential harm and maintain dignity, and to respect the wishes and preferences of different family members, whilst also being mindful of the needs of others who live in the home.

From our own observations of working patterns, pressures and priorities, there was limited evidence of staff's own needs being attended to. One member of staff had been on duty for many hours before bringing a sausage roll from the kitchen to eat at our meeting, only to be called back to the floor before she could finish. Any yet, despite evident pressures, all participants expressed a commitment to the job and to the older people they support.

\section{Discussion}

Applying an ethic of care perspective to the findings underscores that while staff were generally attentive to the needs and aspirations of each resident and to their responses, they were often unable to meet those needs competently through hand-on care giving due to time constraints, competing demands, conflicting messages and pressures to keep up appearances. In Tronto's (1993) terms, the customary conflation of the transactional 'taking care of' and relational 'care giving' could not be sustained. Organisational and systemic failure to attend to the needs of 
staff was coupled with a tendency for responsibilities for the most complex ethical and practical negotiations and balancing acts to land on those on the ground.

In the care home setting, little consideration is given to the everyday ethical and practical dilemmas care staff experience as a result of tensions between conflicting requirements. It is not surprising that food and eating were such a predominant concern of care home staff, given the sharp ethical dilemmas presented, as one carer expressed it: It's finding the balance. You can be very person centred, but if they don't want to get up and don't want to eat do you let them starve to death? There was also the tension expressed by staff between their desire to promote resident autonomy during mealtimes whilst also ensuring that each resident received sufficient nutrition. These are only two of multiple examples of working in a care home which requires balancing choice, reasonable risk and the duty of care in the context of group living. There is a lack of acknowledgement about the complexity of so-called 'basic' care work, lack of attention to the particular forms of knowledge that care staff have, and lack of realism about what's humanly possible in a climate of limited resources. Despite this, the senior carers participating in this work remain hugely enthusiastic about the work that they do. They grasp opportunities to build and strengthen relationships with the unique older people they care for, and to discover and support the things that matter to them, including through the use of knowledge acquired in the private sphere, emotions and through more embodied expressions of autonomy which individualist assumptions privileging rationality and cognition overlook. Indeed, the growing emphasis on independence, consumer choice and control in policy and wider public discourse must be reconciled with the reality of the increasingly complex needs of advanced old age.

Bauman (1998) has cautioned that consumerism is a double-edged sword, warning that there will always be winners and losers. The polarisation between those empowered to choose and those whose choices are restricted to the bare essentials is evident. However, rather than 
erecting yet another boundary (Barnes 2012), in relating our findings to the wider personalisation literature, we found that familiar tensions generated by the fundamental flaws of choice-based models of personalisation were thrown into sharp relief in the care home context. Specifically, questions posed in community settings about the nature and content of choices and the conditions in which they are offered assume a new saliency, and the overblown attention to pre-set menu options chimes with Hart's (2014) concerns about offering older people the choice between 'two baths a week or a shower every day'.

The dilemmas that care home staff face in trying to navigate the tensions between competing ethical imperatives are only too evident when addressing aspects of daily life as fundamental as eating and drinking. Ultimately, expanding the personalisation debate into care homes for older people calls attention to our emotional, relational, embodied nature and forces us to confront the dependencies and interdependencies that that deep old age lays bare, but that characterise all our lives. It supports consideration of the ways in which people with advanced dementia continue to express their autonomy and takes seriously their continued contribution to decision making, mediated by the ethical sensibilities of the so-called 'unskilled' staff that support them. The policy failure to embrace the frailty and finitude of many older residents perhaps reflects a societal reluctance to confront the realities of advanced old age and to recognise dependency as part of the human condition. Choice and control is not only a policy shield against a feared inordinate need for care, it is also a societal shield against our own (future) vulnerabilities (Sevenhuijsen 2003).

Choice and control also underplay the therapeutic and relational role of the practitioner as system navigator, and effectively move ethical responsibility for managing complexity to the individual. This runs counter to the need for attentiveness and subtle modes of engagement to understand the person and their preferences, in face of increasing challenges with health and often cognition. The experience of many practitioners is that the assumptions of a system based 
on rational autonomy can result in further disempowerment of those with higher levels of need, and increased inequalities, characterised as "a contradiction between a policy objective and its actual practice at its sharpest" (Benoot et al 2020, p18). Collective dialogue learning offers opportunities to navigate some of these tensions (Andrews et al 2020).

\section{Conclusion}

In bringing together consumerist and right-based arguments, predominant UK personalisation policy mechanisms contain fundamental flaws, masking irreconcilable differences behind the seemingly impenetrable sword and shield of choice-and-control. In this study, expanding the personalisation debate into the everyday realities of the collective life of the care home exposed the complexity and fluidity of decision making and the often overlooked difficulties faced by frontline staff. Food and eating represent the meeting point of one of the most consumer-oriented aspects of our lives and a basic requirement for sustaining life, rendering us increasingly dependant on relationships with others as physical and cognitive abilities decline. Care staff must navigate the tensions between the duties to protect, to care, to respect resident autonomy and to be respectful of the things that matter to relatives, amidst the competing demands of group living. This mirrors the findings of a recent international review of self-directed funding schemes in care at home for older people, which adopted an ethic of care lens and which found that "the glossy appeal of choice" tends to obfuscate the complexities in working conditions, interpersonal relationships, and the messy politics of services (Fitzgerald and Murphy 2018, p54).

In the care home context the 'moral authority' invested in 'choice and control' was forced to confront frequently overlooked dimensions of ethical practice on a daily basis and the conflation of the transactional 'taking care of' and the relational 'care giving' could not be sustained. Far from being a limiting case for personalisation, the care home constitutes fertile 
ground for getting behind the sword and shield of 'choice and control', exposing and exploring key limitations, and for advancing a more relational, inclusive and sustainable conceptualisation of personalisation. This involves a step back from the equation of personalisation with individualisation, or the pursuit of personal preferences in all aspects of life. Compromise is a necessary part of the relational care required to achieve outcomes for people, and to protect both an ethic of care and the capabilities of older people (Rummery 2011).

Importantly, the care home can also be construed as a microcosm of the wider social care system, in which previously expressed concerns about the limits of choice-based models of personalisation in community settings are thrown into sharp relief and cannot be ignored. The utility of personal outcomes as a 'meaning focused approach' to improving quality of life of care home residents has been recently promoted by McConnell and Meyer (2019). Incorporating relational outcomes alongside wellbeing and quality of life outcomes, it acknowledges the requirement to negotiate the perspectives of the person, the family and the practitioner in the context of organisational necessities (Cook and Miller 2012). In this study we find that this aligns with the ethic of care principles of attentiveness and responsiveness as a nuanced 'way of being' with residents, which accommodates choices and preferences within a relational approach, as compared with a menu driven approach to personalisation.

As well as highlighting the limitations of a choice and control-based model of personalisation, this study brings into focus the necessity of addressing key structural considerations. Indeed, most recently, COVID19 has brought such requirements into sharp relief. Providing care staff with support, resources and recognition will be critical if care provision is to be sustained into the future. This requires review of the underfunded, market-based model of care home provision. There are also opportunities to build on successful approaches to using dialogue- 
learning amongst heterogenous groups of older people, carers, staff and regulators to help progress beyond 'them and us' divisions based on misperceptions (Andrews et al 2020). Scotland is currently undergoing a programme of adult social care reform, which has gained new impetus with the particularly devastating impact of COVID19 on residents and staff in care homes. This reform provides a timely opportunity to engage all involved in conceptualising an approach to personalisation which marries wellbeing, quality of life and relational outcomes for people with the principles of an ethic of care.

\section{References}

Andrews, N., Gabbay, J. Le-May, A. Miller, E. Petch, A. and O’Neill, M. (2020). Story, dialogue and caring about what matters to people: progress towards evidence-enriched policy and practice, Evidence \& Policy, online version,

DOI: $10.1332 / 174426420 X 15825349063428$

Barnes, M. (2011). Abandoning Care? A Critical Perspective on Personalisation from an Ethic of Care. Ethics and Social Welfare 5, 153-67.

Barnes, M. (2012). Care in Everyday Life: An ethic of care in practice. The Policy Press: Bristol.

Bauman, Z., (1998). Globalisation: the human consequences. Polity Press: Cambridge.

Benoot, T., Dursin, W., Verschuere, B. and Roose, R. (2020). Lessons from Ricoeur's 'capable human being' for practices of personalisation in three European countries, Disability and Society, https://doi.org/10.1080/09687599.2020.1769561 
Beresford, P. (2014) Advancing the positives of personalisation /person-centred support: a multi-perspective view. In Needham, C. and Glasby, J. (eds) Debates in Personalisation (2014). Policy Press: Bristol.

Boxall, K., Dowson, S. and Beresford, P. (2009). Selling Individual Budgets, Choice and Control: Local and Global Influences on UK Social Care Policy for people with Learning Difficulties, Policy and Politics 37, 499-515.

Care Act (2014) http://www.legislation.gov.uk/ukpga/2014/23/contents/enacted/data.htm Cook, A. and Miller, E. (2012). Talking Points: A personal Outcomes Approach. Joint Improvement Team: Edinburgh.

CMA (2017) Care homes market study, CMA London

Demos. (2014). A vision of care fit for the twenty-first century. The Commission on Residential Care: London

Eccles, A. and Cunningham, I. (2018). The enablers and barriers to voluntary sector organisations providing personalised support through delivery of Self-Directed Support, University of Strathclyde, Glasgow.

Fisher, B., and Tronto, J. (1990) Towards a Feminist Theory of Caring. In Abel, E., and Nelson, M. (eds) Circles of Care Work and Identity in Women's Lives. State University Press: New York.

Franklin, B. (2014). The future care workforce. ILC-UK: London.

Fitzgerald, M. and Murphy, C. (2018) Questioning "choice": A multinational metasynthesis of research on directly funded home-care programs for older people, Health and Social Care in the Community, DOI: 10.1111/hsc.12646

Froggatt, K., Davies, D. and Meyer, J. (2009). Research and Development in care homes: setting the scene. In: Froggatt K, Davies S, Meyer J, (eds) Understanding Care Homes: a research and development perspective. Jessica Kingsley Press, London. 
Glasby, J. and Needham, C. (2014). Conclusion: Glass half empty or half full. In Needham, C. and Glasby, J. (eds). Debates in Personalisation (2014). Policy Press: Bristol.

Harnett, T. and Jonson, H. (201)6. Shaping nursing home mealtimes, Ageing and Society, 37, 823-44.

Hart, V. (2014). ‘A View from Social Work Practice.' In Debates in personalization, edited by C. Needham and J. Glasby. Bristol: Policy Press.

Hurtley, R. (2004). The developing culture in its political context. In Perrin T (ed). The New Culture of Therapeutic Activity with Older People. Speechmark Publishing Ltd. Oxon Jeon, Y., Simpson, J., Li, Z., Cunich, M., Thomas, T., Chenoweth, L., and Kendig, H. (2015). Cluster Randomized Controlled Trial of An Aged Care Specific Leadership and Management Program to Improve Work Environment, Staff Turnover, and Care Quality. Journal of the American Medical Directors Association (JAMDA), 16, 629.e19-629.e28.

Joseph Rowntree Foundation (JRF). 2009. Older People's Vision for Long-term Care. JRF: York.

Kadri, A., Rapaport, P., Livingston, G., Cooper, C., Robertson, S. and Higgs, P. (2018). Care workers, the unacknowledged persons in person-centred care: A secondary qualitative analysis of UK care home staff interviews. PLoS ONE 13, e0200031. https://doi.org/10.1371/journal.pone.0200031

Kennedy, J. (2014) John Kennedy's Care Home Inquiry, JRF: York.

Keyes, S., Webber, S. and Beveridge, K. (2015). Empowerment through care: Using dialogue between the social model of disability and an ethic of care to redraw boundaries of independence and partnership between disabled people and services. European Journal of Disability Research, 9, 236-248. 
Kontos, PC., Miller, K.L., Mitchell, G.J. and Cott, C.A. (2011). Dementia care at the intersection of regulation and reflexivity: a critical realist perspective, J Gerontol B Psychol Sci Soc Sci. 66, 119-28.

Law Commission. (2011). Adult Social Care. Stationery Office: London. Available at: http://www.scottishcare.org/people-as-partners/blog/wp-content/uploads/Paper-on-SDS-andresidential-care-challenges $1 . p d f$

Lloyd, L. (2010) The Individual in Social Care: the Ethics of Care and the 'Personalisation Agenda' In Services for Older People in England. Ethics and Social Welfare, 4, 188-200.

Lloyd, L. (2014). Can personalisation work for older people? In Needham, C. and Glasby. J. (eds). Debates in Personalisation. Policy Press: Bristol.

Lymbery, M. (2013). Austerity, personalisation and older people: the prospects for creative social work practice in England, European Journal of Social Work, DOI: 10.1080/13691457.2013.830594.

McConnell, E. and Meyer, J. (2019). Assessing Quality for People Living With Dementia in Residential Long-Term Care: Trends and Challenges, Gerontology \& Geriatric Medicine, 5: 17.

Merrell, J., Philpin, S., Warring, J., Hobby, D. and Gregory, V. (2012). Addressing the nutritional needs of older people in residential care home, Health and Social Care in the Community, 20, 206-215.

Midwinter, E. (2011). Care Homes: A Historical Perspective. In Lievesely, N., Crosby G, and Bowman, C. (eds). The Changing Place of Care Homes. BUPA and the Centre for Policy on Ageing Miller, E. (2011). Getting Back to What Matters. Dunedin: Edinburgh. 
Miller, E. and Barrie, K. (2015). Learning from the Meaningful and Measurable project:

Strengthening links between identity action and decision-making, Healthcare Improvement Scotland: Glasgow

Mol, A. (2008). The logic of care: Health and the problem of patient choice. Routledge:

Abingdon UK.

Mol, A. (2009). Living with diabetes: Care beyond choice and control. Lancet. 373, 17561757.

Morris, J. (2004). Independent Living and Community Care: A Disempowering Framework, Disability and Society, 19, 427-42.

Needham, C. (2011). Personalising Public Services: Understanding the personalisation narrative. Policy Press: Bristol

Needham, C. and Glasby, J. (2014). Taking stock of personalisation. In Needham, C. and Glasby, J. (eds) Debates in Personalisation. Policy Press: Bristol.

Nolan, M. R., Davies, S., Brown, J., Keady, J. and Nolan, J. (2004). Beyond 'person- centred' care: a new vision for gerontological nursing. Journal of Clinical Nursing, 332, 1180-4.

O'Dwyer, C. (2013). Official conceptualizations of person-centred care. Which person counts? Journal of Aging Studies, 27, 233-242.

Petch, A. Cook, A. and Miller, E. (2013). Partnership working and outcomes: do health and social care partnerships deliver for users and carers? Health and Social Care in the Community, 21, 623-633.

Qureshi, H., Patmore, C., Nicholas, E. and Bamford, C. (1998) Overview: Outcomes of social care for older people and carers. Outcomes in Community Care Practice No.5. Social Policy Research Unit, University of York. 
Royal College of Nursing (RCN). 2012. Persistent challenges to providing quality care: an $R C N$ report on the views and experiences of frontline nurses working in care homes in England, Royal College of Nursing, London.

Rummery (2011) A Comparative Analysis of Personalisation: Balancing an Ethic of Care with User Empowerment, Ethics of Social Welfare, 5, 138-52.

Samuel, M. (2010) The doubts remain, Community Care, 20th May, 16-7.

Scottish Care. (2012). Organisational and Infrastructure Challenges in Relation to SelfDirected Support in Care Home Services. Available at: http://www.scottishcare.org/people-aspartners/blog/wp-content/uploads/Paper-on-SDS-and-residential-care-challenges1.pdf Scottish Government. (2014). The Future of Residential Care in Scotland: Taskforce Report, Scottish Government: Edinburgh.

Self-Directed Support Act (Scotland). (2013). Available at: http://www.legislation.gov.uk/asp/2013/1/contents/enacted Sevenhuijsen, S. (1998). Citizenship and the ethics of care: Feminist considerations of justice, morality and politics. Routledge: London and New York.

Sevenhuijsen, S. (2003). The place of care: the relevance of the feminist ethic of care for social policy. Feminist Theory 4, 179-97.

Sharp, C., Dewar, B., Barrie, K. and Meyer, J. (2017). How being appreciative creates change - theory in practice from health and social care in Scotland, Action Research, 16, 223-243.

Smale, G., Tuson, G., Biehal, N. and Marsh, P. (1993). Empowerment, Assessment, Care Management and the Skilled Worker, National Institute for Social Work Practice and Development Exchange, HMSO: London. 
Tanner, D., Ward, L., Ray, M. (2017). Paying our own way: Application of the capability approach to explore older people's experiences of self-funding social care. Critical Social Policy, 38, 262-282.

Tronto, J.C. (1993). Moral Boundaries. A Political Argument for an Ethic of Care. Routledge: New York and London.

United Nations (2019) World Population Ageing. UN: Department of Economic and Social Affairs: NY.

Ward, L. and Gahagan, B. (2010). Crossing the Divide between Theory and Practice: Research and an ethic of Care, Ethics and Social Welfare, 4, 210-216.

Whear, R., Abbott, R., Thompson-Coon, J., Bethel, A., Hemsley, A., Stahl-Timmons, W. and Stein, K. (2014). Effectiveness of Mealtime Interventions on Behavior Symptoms With Dementia Living in Care Homes: A Systematic Review, JAMDA, 15, 185-193.

Young, K. (2020) Where is the person in personalisation? Experiences of people with learning disabilities and their families in Glasgow. $\mathrm{PhD}$ thesis http://theses.gla.ac.uk/81447/ 